\title{
Inauguration of the newly launched journal of Green Manufacturing Open: how does manufacturing industry cope with rapid emerged environment and climate crisis in this planet
}

\author{
Hongchao Zhang \\ Department of Industrial, Manufacturing and Systems Engineering, Texas Tech University, Lubbock, TX 79409, USA. \\ Correspondence to: Prof. Hongchao Zhang, Department of Industrial, Manufacturing and Systems Engineering, Texas Tech \\ University, Lubbock, TX 79409, USA. E-mail: Hong-Chao.Zhang@ttu.edu. \\ How to cite this article: Zhang H. Inauguration of the newly launched journal of Green Manufacturing Open: how does \\ manufacturing industry cope with rapid emerged environment and climate crisis in this planet. Green Manuf. Open 2023;1:1. \\ https://dx.doi.org/10.20517/gmo.2022.01
}

Received: 8 Feb 2022 Accepted: 8 Feb 2022 Available online: 12 Feb 2022

Academic Editor: Hongchao Zhang Copy Editor: Yue-Yue Zhang Production Editor: Yue-Yue Zhang

\section{A SHORT STORY}

Let me start with a short story that is also my personal experience for this inauguration editorial. On 10 February 2021, I was at my new home in Austin, the capital of Texas State, USA. With an evening darkness fallout, the outside temperature dramatically dropped to below $0{ }^{\circ} \mathrm{F}$. A series of winter storms swept over Central Texas. We experienced a power outage, then consequently the water supply stopped, and finally heating gas also diminished in the gas pipe. This situation continued with no power, no water, and no gas, while the outside temperature continued dropping consecutively over eight days, from 10 to 18 February 2021. The outdoor temperature broke the historical low records for 7-8 days with snowstorms and icing ${ }^{[1]}$. The indoor temperature in my bedroom dropped to $10^{\circ} \mathrm{F}$, which is about $-14{ }^{\circ} \mathrm{C}$. In Addition, there was no hot water, no hot meals, no gas, and no heating. While people discuss how to deal with such urgent weather crises, we should keep in mind that climate change and global warming are the origins to cause these disasters. 


\section{UNITED NATIONS FRAMEWORK CONVENTION ON CLIMATE CHANGE}

In fact, the United Nations addressed this crisis in the early part of the $1990 \mathrm{~s}^{[2]}$. Under the leadership of the United Nations Framework Convention on Climate Change (UNFCCC) $)^{[2]}$, participating countries agreed and formed Kyoto Protocol ${ }^{[3]}$ in 2008, the Copenhagen Accord $^{[4]}$ in 2009, and the Paris Agreement ${ }^{[5]}$ in 2016. In addition, not long ago, we, all parties, attended the meeting from 31 October to 13 November 2021 in Glasgow, UK, and drafted the newest document, which is titled the Glasgow Climate Pact ${ }^{[6]}$. Therefore, one can see that climate change and global warming have become one of the top priorities for humans to deal with in this century.

\section{THE MOTIVATION (VISION)}

One of the original motivations to launch this unique new journal is to encourage and promote research activities of manufacturing industries to reduce and reverse climate change from the manufacturing industrial aspect. Green Manufacturing Open (GMO) will provide a platform for exchanging research ideas, methodologies, and technologies as well as suggestions on how to green manufacturing activities in all aspects. In fact, greening manufacturing has not been absent from the UNFCCC since the early 1990 . Originally, these efforts were named "environmentally conscious design and manufacturing", also known as "lifecycle assessment" ${ }^{[]]}$. The main efforts were focused on mitigating and reducing all environmental impacts throughout the entire lifecycle of a product from the product design, process design and planning, manufacturing processing, and packaging, through the product's utilization, until the end-of-life (EoL) treatments. During this time period, EoL electronic product disassembly, recycling, and material recovery were some of the active and prominent areas. Sustainable manufacturing is a relatively new phrase used to denote the activities discussed above. In the meantime, based on the Kyoto Protocol ${ }^{[3]}$ and Paris Agreement ${ }^{[5]}$, reducing the carbon emission of manufacturing activities is included in the sustainable manufacturing spectrum, which includes research for recording, calculation, and configuration of carbon footprints from manufacturing industries. Low carbon manufacturing, reverse supply chain management, greening supply chain, etc., are some substitutable names for this consideration.

\section{THE SCOPE}

The scope of the GMO will comprehensively consist of total environmental impact, natural resources efficiency, and $\mathrm{CO}_{2}$ emission mitigation within the entire product life cycle. The goals of green manufacturing are to minimize the impact on the environment and maximize resource efficiency during the entire product life cycle from product design, manufacturing, packaging, transportation, and utilization to EoL recovery, recycling, and disposal. Therefore, we may say that green manufacturing involves the intersection and integration of manufacturing, environmental, natural resource, and energy consumption fields. It is not only a behavior with significant social benefits, but also an effective means to achieve significant economic benefits and the goal of a circular economy. I still remember, about 20 years ago, that I had a very inspiring and meaningful conversation with a very respected scholar, who is also my mentor. He made a very interesting hypothesis "if we consider all of the human being's efforts on manufacturing from the very beginning, all of the human's activity is a process to convert raw materials into a meaningful product that our human can use or consume it that can increase our human's living standard. Yes, no doubt, that is correct, but if you imagine that the natural resources in this planet are not infinity. If we do not close the loop of the raw materials from virgin to a product, then to raw materials again, our human sooner or later will be facing the scenarios that natural resources are exhausted." He continued: "Then if you consider that, in the last over 1000 years, all of our human's effort converting raw materials into a meaningful product, which is only denoted halfway of the total material life cycle. Then can you imagine how long the way for our human beings will have to go to close this loop of raw materials' entire lifecycle? That is a material life cycle that enclose virgin materials to be manufacturing processed to become a product 
then after our consuming, we will need to make the end of life product to become raw materials again." While there is no definite answer to his question of how many years it will take to close this loop, my imagination draws me to this way. Even without another thousand years, some hundred years is probably a reasonable estimation. The conclusion is that we still have long ways to go for our proposed idea of greening manufacturing.

\section{IN THIS YEAR AND THE NEAR FUTURE}

Today, it is too early to summarize the whole research scope of greening manufacturing. Because greening manufacturing is still in its infancy, for the same reason, it is impossible to itemize overall research tools, methodologies, and technologies as well as the theoretical areas that require and can contribute to greening manufacturing. However, this is our way that we will go step by step toward the goals. That is the basic strategy for this new journal. We will publish papers that reflect the original research works lying in all aspects of green manufacturing. This year, we plan to publish two issues with general submissions and reviewing processes. We expect the first issue to be published in late summer of 2022, while the second issue will be published at the end of this year. Currently, we are planning to publish $4-5$ issues in 2023 . While we will continue to publish four regular issues, we may also seek calls for a Special Issue in 2023 based on the Guest Editor's special interests.

\section{DECLARATIONS}

\section{Authors' contributions}

The author contributed solely to the article.

\section{Availability of data and materials}

Not applicable.

\section{Financial support and sponsorship}

None.

\section{Conflicts of interest}

The author declared that there are no conflicts of interest.

\section{Ethical approval and consent to participate}

Not applicable.

\section{Consent for publication}

Not applicable.

\section{Copyright}

(c) The Author(s) 2022.

\section{REFERENCES}

1. February 2021 Historical Winter Storm Event South-Central Texas. Available from: https://www.weather.gov/media/ewx/wxevents/ewx-20210218.pdf [Last accessed on $10 \mathrm{Feb} 2022]$.

2. What is the United Nations Framework Convention on Climate Change? Available from: https://unfecc.int/process-and-meetings/theconvention/what-is-the-united-nations-framework-convention-on-climate-change [Last accessed on 10 Feb 2022].

3. What is the Kyoto Protocol? Available from: https://unfccc.int/kyoto_protocol [Last accessed on 10 Feb 2022].

4. Copenhagen Climate Change Conference - December 2009. Available from: https://unfccc.int/process-and-meetings/conferences/pastconferences/copenhagen-climate-change-conference-december-2009/copenhagen-climate-change-conference-december-2009 [Last accessed on 10 Feb 2022].

5. The Paris Agreement. Available from: https://unfccc.int/process-and-meetings/the-paris-agreement/the-paris-agreement [Last accessed on 10 Feb 2022]. 
6. Glasgow Climate Pact. Available from: https://unfccc.int/documents/310475 [Last accessed on 10 Feb 2022].

7. Klöpffer W. Life cycle assessment: from the beginning to the current state. Environ Sci Pollut Res Int 1997;4:223-8. DOI PubMed 